\title{
Application of heat transfer correlations for FC-72 flow boiling heat transfer in minichannels with various orientations
}

\author{
Magdalena Piasecka ${ }^{\mathrm{a}}$ \\ Kielce University of Technology, Department of Mechanics, Al. 1000-lecia P.P. 7, PL-25-314 Kielce, Poland
}

\begin{abstract}
The paper presents the results of using known correlations for boiling heat transfer in a minichannel $1 \mathrm{~mm}$ deep, $40 \mathrm{~mm}$ wide and $360 \mathrm{~mm}$ long, with different spatial orientations. The heating element for FC-72 flowing laminarly in the minichannel is a single-sided microstructured foil. Liquid crystal thermography was used for measuring the temperature distribution on the plain side of the foil. The observations of the flow structures were carried out on the microstructured side of the foil contacting fluid in the minichannel. A number of correlations for boiling heat transfer have been used in calculations. It was found that the majority of correlations enabled the predicting of heat transfer coefficient within an acceptable error limit $( \pm 30 \%)$ only in a specific orientation of the channel. For the horizontal channel, position $0^{\circ}$, the highest compliance occurred when Mikielewicz et al. correlation was applied, for the vertical channel - when Liu and Winterton correlation was used and for horizontal channel, position $180^{\circ}$ - by the application of Cooper correlation. The own correlation, with taken account for the microstructured heating wall, was proposed in two forms: for saturated boiling and for boiling incipience and subcooled boiling. Most experimental data show congruence with theoretical correlations with the tolerance $\pm 35 \%$.
\end{abstract}

\section{Introduction}

Heat transfer in small channels has been dealt with significant attention over the last few years, especially for application to electronics cooling. Mini heat exchangers are used to provide higher cooling capability for new technologies. It means a reduction of their sizes and costs, while the power is identical. Owing to the change of the state which accompanies flow boiling in small channels, it is feasible to meet contradictory needs simultaneously, i.e. obtain a heat flux as large as possible at small temperature difference between the heating surface and the saturated liquid and, at the same time, retain small dimensions of heat transfer systems. The use of microstructured surfaces allows additional intensification of the process. In contrast to the single phase flow in small channels which are usually described with equations for conventional channels, flow boiling is affected by the confinement of bubbles. The series of studies pursued at the Kielce University of Technology includes research on flow boiling heat transfer in a cooling fluid flow along the minichannel with plain or microstructured heating walls and various orientations. The results were described in numerous publications, e.g. [1-7]. This paper compares results of the heat transfer during developed boiling in a minichannel with studies to be carried out by the author of this paper, using correlations developed by other researchers.

\footnotetext{
$\overline{{ }^{\mathrm{a}} \text { Corresponding author: tmpmj@tu.kielce.pl }}$
}

\section{The experimental database}

\subsection{Experimental stand}

The essential part of the experimental stand is the test section with a rectangular minichannel (Fig. 1a, \#1), $1 \mathrm{~mm}$ deep, $40 \mathrm{~mm}$ wide and $360 \mathrm{~mm}$ long. The heating element for FC-72 flowing in the minichannel (\#1) was the thin alloy foil (\#2) designated as Haynes-230. The foil is microstructured on the side which comes into contact with fluid in the channel. Two types of microstructured heating surfaces: one with micro-recesses distributed evenly, and another with mini-recesses distributed unevenly, were used. The micro-recesses were performed by laser drilling. The diameter of the single micro-recess is usually $10 \mu \mathrm{m}$, its depth is $3 \mu \mathrm{m} .5 \div 7 \mu \mathrm{m}$ high layers of melted metal deposit annularly around the recesses, forming structures that can be named as "craters". Microrecesses are evenly distributed every $100 \mu \mathrm{m}$ in both axes. The mini-recesses were obtained by spark erosion. The melted metal foil and an electrode material, a few $\mu \mathrm{m}$ high, reaching locally $5 \mu \mathrm{m}$, accumulates around the recesses. The depth of the cavity craters is usually below $1 \mu \mathrm{m}$. It is possible to observe both surfaces of the channel through glass panes. One pane (\#4a) allows 
observing changes in the temperature distribution on the plain side of the foil thanks to the liquid crystal thermography. The latter one (\#4b) allows to observe the two-phase flow patterns on the microstructured foil side. K-type thermocouples and pressure converters are installed in the inlet and outlet of the minichannel. The test section was oriented vertically with the bottom-up flow and horizontally at two different positions set in various angles to the plate, i.e. 0, 90 and 180 degrees. The system consists of three sections: data and the image acquisition system with digital cameras; data acquisition system and with a computer with special software and lighting systems. All these are crucial parts of the research set up. The experimental set-up was presented in detail in [1-6]. 3D photos of the microstructured foil with micro-recesses (b) and mini-recesses (c) are presented in Fig. 1b,c. Detailed information about the accuracy of the heating foil temperature measurements with liquid crystal thermography and other experimental data errors are described in [2].

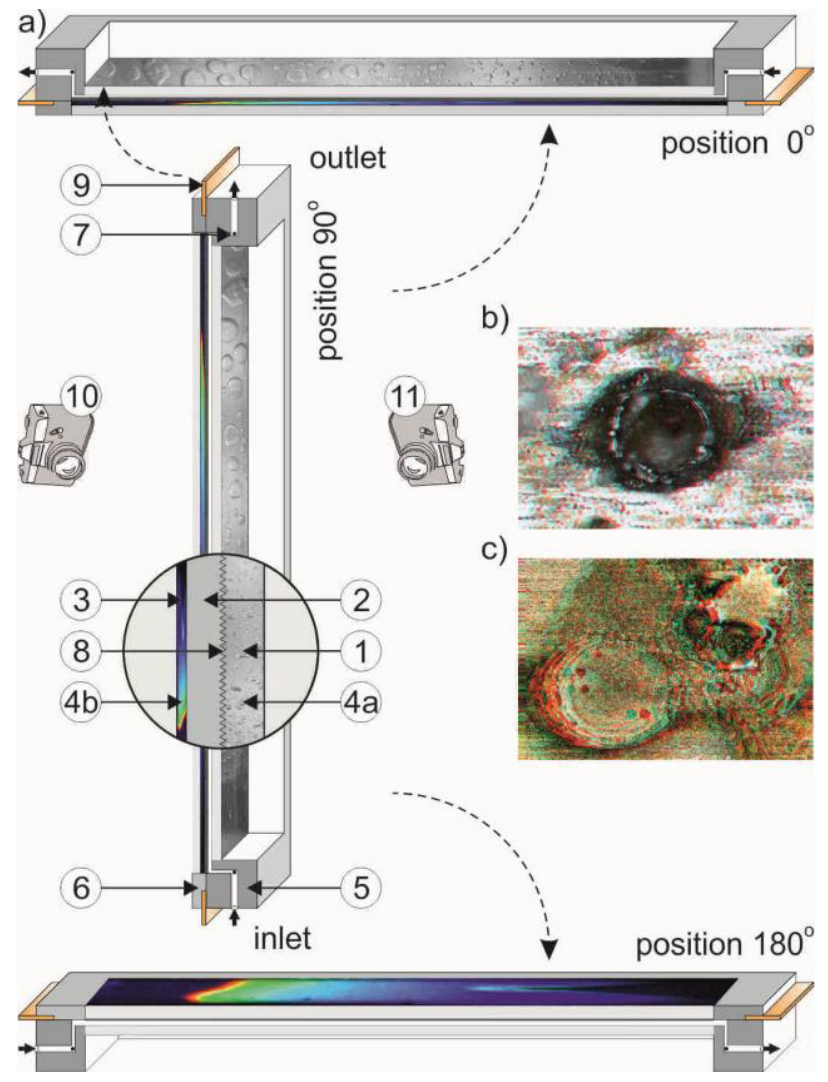

Figure 1. a) The diagram of the test section: \#1-minichannel, \#2-heating foil, \#3-liquid crystal layer, \#4a,b-glass plate, \#5-channel body, \#6-front cover, \#7-thermocouple, $\# 8$-enhanced side of the foil, \#9-copper element, \#10-digital camera, \#11-digital SLR camera; b,c) 3D photos of the microstructured foil with: a micro-recesses (b) mini-recesses (c)

\subsection{Experimental heat transfer coefficient determination}

Various methods of the determination of the local heat transfer coefficient in the two-dimensional approaches, obtained from solving the inverse problem were proposed. The finite element method in combination with
Trefftz functions [2] was one of these solutions, while others employ include the sensitivity coefficient method or apply the nodeless method. The above mentioned methods employ Trefftz functions. Here, the simple onedimensional approach was used [1]. The resulting heat transfer coefficient for the subcooled boiling was determined by the eq. (1a), while that for saturated boiling - by eq. ( $1 \mathrm{~b})$, as follows:

$$
\begin{gathered}
\alpha(x)=\frac{I \cdot \Delta U / A_{F}}{T_{F}(x)-T_{l}(x)-\frac{I \cdot \Delta U}{A_{F}} \cdot \frac{\delta_{F}}{\lambda_{F}}} \\
\alpha(x)=\frac{I \cdot \Delta U / A_{F}}{T_{F}(x)-T_{s a t}(x)-\frac{I \cdot \Delta U}{A_{F}} \cdot \frac{\delta_{F}}{\lambda_{F}}}
\end{gathered}
$$

\section{Review of boiling heat transfer correlations}

The selected boiling heat transfer correlations chosen for the analysis are presented below. The following correlations were presented: for pool boiling (Cooper) and for saturated flow boiling; subsequently for: conventional channels (Shah, Gungor and Winterton, Liu and Winterton) and minichannels or channels of small hydraulic diameter (Lazarek and Black, Tran et al., Kew and Cornwell, Kandlikar and Steinke, Warrier et al. Agostini and Bontemps, Mikielewicz et al., Sun and Mishima, Bertsch et al., Li and $\mathrm{Wu}$, Dutkowski).

\subsection{Cooper correlation}

Cooper (1984) [8] proposed the correlation for nucleate boiling heat transfer. It was dedicated for pool boiling. Some references suggest applying it also for flow boiling:

$$
\alpha_{n b}=55 \cdot p_{r}{ }^{0.12-0.2 \cdot \log R a} \cdot\left(-\log p_{r}\right)^{-0.5} \cdot M^{-0.5} \cdot q_{w}{ }^{0.67}(2)
$$

Research conducted in the experimental stand described in [9] focused on pool boiling heat transfer on surfaces with micro-cavities [10] which were similar to that used in the author's research on flow boiling. Comparison of results for flow boiling in a minichannel and pool boiling indicates that calculated heat transfer coefficients vary depending on the type of flow boiling (subcooled, saturated) and of saturated boiling development.

\subsection{Shah correlation}

Shah correlation (1982) [11] was based on experimental data obtained for $d_{h}=6 \div 25.4 \mathrm{~mm}$ (780 points), tested for the fluids: R-11, R-12, R-22, R-113, cyclohexane, water

$$
\alpha_{T P}=\max (E, S) \cdot \alpha_{l}
$$

where $\alpha_{l}$ is calculated from Dittus-Boelter correlation:

$$
\left.\begin{array}{l}
\alpha_{l}=\left(0.023 \cdot R e_{l}^{0.8} \cdot \operatorname{Pr}_{l}{ }^{0.4}\right) \cdot\left(\lambda_{l} / d_{h}\right) \\
\text { for } N>1 \quad S=1.8 / N \\
E=230 \cdot B o^{0.5} \text { for } B o>3 \cdot 10^{-5} \\
E=1+46 \cdot B o^{0.5} \text { for } B o<3 \cdot 10^{-5}
\end{array}\right\}
$$




$$
\left.\begin{array}{l}
\text { for } 0.1<N \leq 1 \quad S=1.8 / N^{0.8} \\
E=F \cdot B o^{0.5} \cdot \exp \left(2.74 \cdot N^{-0.15}\right) \\
F=14.7 \text { for } B o \geq 0.0011 \\
F=15.43 \text { for } B o<0.0011
\end{array}\right\}
$$

$N=N_{C o}$ for vertical pipes and horizontal pipes if

$$
F r_{l} \geq 0.04
$$

$N=0.38 \cdot F r_{l}^{-0.3} \cdot N_{C o}$ for vertical pipes if $F r_{l}<0.04$

$N_{C O}$ is defined:

$$
N_{\text {Co }}=\left(\frac{1-X}{X}\right)^{0.8} \cdot\left(\frac{\rho_{v}}{\rho_{l}}\right)^{0.5}
$$

In Dittus-Boelter correlation, the Reynolds number should be calculated as:

$$
\operatorname{Re}_{l}=\frac{G \cdot(1-X) \cdot d_{h}}{\mu_{l}}
$$

\subsection{Gungor and Winterton correlation}

Gungor and Winterton correlation (1987) [12] was proposed as modification of Chen correlation, for R-11, $\mathrm{R}-12, \quad \mathrm{R}-22, \quad \mathrm{R}-113, \mathrm{R}-114$, diethylene glycol, $d_{h}=2.95 \div 32 \mathrm{~mm}$, vertical and horizontal channels, in the following form:

$$
\alpha_{T P}=\left(S \cdot S_{2}+F \cdot F_{2}\right) \cdot \alpha_{l}
$$

$\alpha_{l}$ - Dittus-Boelter correlation, eq. (4)

$$
\begin{gathered}
S=1+3000 \mathrm{Bo}^{0.86} \\
S_{2}=\left\{\begin{array}{lc}
F r_{l}^{\left(0.1-2 F r_{l}\right)} & \text { if horizontaland } F r<0.05 \\
1 & \text { otherwise }
\end{array}\right. \\
F_{2}= \begin{cases}F r_{l}{ }^{1 / 2} & \text { if horizontaland } F r<0.05 \\
1 & \text { otherwise }\end{cases}
\end{gathered}
$$

\subsection{Liu and Winterton correlation}

Liu and Winterton (1991) [13] proposed the following equation for subcooled and saturated boiling:

$$
\alpha_{T P}=\sqrt{\left(F \cdot \alpha_{l}\right)^{2}+\left(S \cdot \alpha_{n b}\right)^{2}}
$$

$\alpha_{l}$ - Dittus-Boelter correlation, eq. (4)

$\alpha_{n b}$ - Cooper correlation, eq. (2)

$$
\begin{aligned}
& F=\left[1+X \cdot \operatorname{Pr}_{l} \cdot\left(\rho_{l} / \rho_{v}-1\right)\right]^{0.35} \\
& S=\left(1+0.055 \cdot F^{0.1} \cdot R e_{l}^{0.16}\right)^{-1}
\end{aligned}
$$

Tested data were similar for those in Gungor and Winterton correlation.

\subsection{Lazarek and Black correlation}

Lazarek and Black (1982) [14] proposed flow boiling heat transfer correlation based upon 738 points of R-113, $d_{h}=3.15 \mathrm{~mm}$;

$$
\alpha_{T P}=\left(30 \cdot R e_{l}^{0.857} \cdot B o^{0.714}\right) \cdot\left(\lambda_{l} / d_{h}\right)
$$

\subsection{Tran et al. correlation}

Tran et al. (1996) [15] conducted flow boiling heat transfer experiments for R-12, for small horizontal channels, $d_{h}=2.46 \mathrm{~mm}, 2.92 \mathrm{~mm}$ :

$$
\alpha_{T P}=840000 \cdot\left(B^{2} \cdot W e_{l}\right)^{0.3} \cdot\left(\rho_{l} / \rho_{v}\right)^{-0.4}
$$

\subsection{Kew and Cornwell correlation}

Kew and Cornwell (1997) [16] modified Dittus-Boelter correlation, introducing vapour quality, data for R-141b, $d_{h}=1.36 \div 3.69 \mathrm{~mm}$.

$$
\alpha_{T P}=\alpha_{l} \cdot(1-X)^{-0.143}
$$

$\alpha_{l}$ - Dittus-Boelter correlation, eq. (4)

\subsection{Kandlikar et Steinke correlation}

Kandlikar and Steinke (2002) [17] correlation utilized the single-phase, liquid only, heat transfer coefficient to predict the nucleate boiling $\alpha_{T P, n b}$ and convective boiling components of turbulent regime $\alpha_{T P, c b}$, as follows

$$
\begin{gathered}
\alpha_{T P}=\max \left\{\begin{array}{l}
\alpha_{T P, n b} \\
\alpha_{T P, c b}
\end{array}\right. \\
\alpha_{T P, n b}=\left[0.6683 \cdot C o^{-0.2} \cdot(1-X)^{0.8} \cdot \alpha_{l}+\right. \\
+1058 \cdot B o^{0.7} \cdot(1-X)^{0.8} \cdot F_{F l} \cdot \alpha_{l} \\
\alpha_{T P, c b}=1.136 \cdot \mathrm{Co}^{-0.9} \cdot(1-X)^{0.8} \cdot \alpha_{l}+ \\
+667.2 \cdot B o^{0.7} \cdot(1-X)^{0.8} \cdot F_{F l} \cdot \alpha_{l} \\
\frac{(f / 2) \cdot \operatorname{Re}_{l} \cdot P r_{l} \cdot\left(\lambda_{l} / d_{h}\right)}{1+12.7(f / 2)^{1 / 2} \cdot\left(P r_{l}^{2 / 3}-1\right)} 10^{4} \leq R e_{l} \leq 5 \cdot 10^{6} \\
\alpha_{l}=\frac{(f / 2) \cdot\left(\operatorname{Re}_{l}-1000\right) \cdot P r_{l} \cdot\left(\lambda_{l} / d_{h}\right)}{1+12.7(f / 2)^{1 / 2} \cdot\left(P r_{l}^{2 / 3}-1\right)} \\
3000 \leq R e_{l} \leq 10^{4} \\
f=\left(1.58 \ln \operatorname{Re}_{l}-3.28\right)^{-2}
\end{gathered}
$$

For laminar flow, $\alpha_{l}$ can be calculated from Dittus-Boelter correlation, eq. (4)

$C o=N_{c o}$, calculated as for eq. (7);

For micro- and minichannels $F r=1$.

In parameter $F_{F l}$ values within the range $0.488 \leq F_{F l} \leq 3.30$, depending on the working fluid were assumed. Correlation was based on data for R-11, R-12，R-113，R-123，R-124，R-134a，R-141b，FC-84, $d_{h}=0.4 \div 2.97 \mathrm{~mm}$

\subsection{Warrier et al. correlation}

Warrier et al. (2002) [18] conducted experiments of both single phase forced convection and nucleate boiling. Their correlation was based on data for FC-84, $d_{h}=0.75 \mathrm{~mm}$, using 5 rectangular minichannels, applied to the developed flow boiling, in the following form: 


$$
\alpha_{T P}=\left[1+6 B o^{1 / 16}-5.3(1-855 B o) X^{0.65}\right] \cdot \alpha_{l}
$$

$\alpha_{l}$ - Dittus-Boelter correlation, eq. (4).

\subsection{Agostini and Bontemps correlation}

Agostini and Bontemps correlation (2005) [19] was based on data for R-134a, $d_{h}=2.01 \mathrm{~mm}, 11$ parallel channels of rectangular cross section $(3.38 \mathrm{~mm} \times 1.47 \mathrm{~mm})$ :

$$
\begin{aligned}
& \alpha_{T P}=28 q_{w}{ }^{2 / 3} \cdot G^{-0.26} \cdot X^{-0.1} \text { when } X<0.43 \\
& \alpha_{T P}=28 q_{w}{ }^{2 / 3} \cdot G^{-0.64} \cdot X^{-2.08} \text { when } X>0.43
\end{aligned}
$$

\subsection{Mikielewicz et al. correlation}

Mikielewicz et al. correlation (2007) [20] focused on R-11, R-12 and R-22; they tested it by using data provided by a number of researchers. For minichannels, the following form of the equation was proposed:

$$
\begin{gathered}
\frac{\alpha_{T P}}{\alpha_{r e f}}=\sqrt{R_{M-S}^{0.76}+\frac{1}{1+P} \cdot\left(\frac{\alpha_{n b}}{\alpha_{r e f}}\right)^{2}} \\
R_{M-S}=\left|1+2\left(\frac{1}{f_{1}}-1\right) \cdot X \cdot C^{-1}\right| \cdot(1-X)^{\frac{1}{3}}+X^{3} \cdot \frac{1}{f_{1 z}} \\
f_{1}=\left(\mu_{l} / \mu_{v}\right)^{0.25} \cdot\left(\rho_{l} / \rho_{v}\right)^{-1} \\
f_{1 z}=\left(\mu_{v} / \mu_{l}\right) \cdot\left(c_{l} / c_{v}\right) \cdot\left(\lambda_{l} / \lambda_{v}\right)^{1.5}
\end{gathered}
$$

The correction $P$ was defined:

$$
P=a \cdot\left(R_{M-S}-1\right)^{b} \cdot R e_{l}^{c} \cdot B o^{d}
$$

2500 experimental data for R-11, R-12 and R-22, from various authors were used for the determination of this correction; coefficients $a, b, c, d$ were determined experimentally and the following dependence was obtained:

$$
\begin{aligned}
& \frac{\alpha_{T P}}{\alpha_{r e f}}= \\
& \sqrt{R_{M-S}^{0.76}+\frac{1}{1+2.53 \cdot 10^{-3} \cdot R e^{1.17} \cdot B o^{0.6} \cdot\left(R_{M-S}-1\right)^{-0.65}} \cdot\left(\frac{\alpha_{n b}}{\alpha_{r e f}}\right)^{2}}
\end{aligned}
$$

where $C o$ - Confinement number, defined as

$$
C o=\frac{1}{d_{h}} \cdot \sqrt{\frac{\sigma}{g \cdot\left(\rho_{l}-\rho_{v}\right)}}
$$

$\alpha_{\text {ref }}$ - Dittus-Boelter correlation, eq. (4),

$\alpha_{n b}$ - Cooper correlation, eq. (2).

\subsection{Sun and Mishima correlation}

Sun and Mishima correlation (1991) [21] was based on Lazarek and Black correlation by introducing Weber number:

$$
\alpha_{T P}=\frac{6 R e_{l}^{1.05} \cdot B o^{0.54}}{W e_{l}^{0.191} \cdot\left(\rho_{l} / \rho_{v}\right)^{0.142}} \cdot \frac{\lambda_{l}}{d_{h}}
$$

The correlation applies the following data: $d_{h}=0.21 \div 6.5 \mathrm{~mm}$. It was based on data for: R-11, R-12, R-123, R-134a, R-141b, R-22, R-404a, R-407c, R-410a, $\mathrm{CO}_{2}$ and water.

\subsection{Bertsch et al. correlation}

Bertsch et al. correlation (2009) [22] was based on data for water, 12 fluid including refrigerants and cryogens and $\mathrm{N}_{2}, d_{h}=0.16 \div 2.92 \mathrm{~mm} ; 3899$ points

$$
\begin{gathered}
\alpha_{T P}=S \alpha_{n b}+F \alpha_{S P} \\
S=1-X \\
\alpha_{S P}=\alpha_{v}+(1-X) \alpha_{l}
\end{gathered}
$$

- for turbulent flow, $\alpha_{v}$ and $\alpha_{l}$ should be calculated from Dittus-Boelter correlation, eq. (4)

- for laminar flow:

$$
\begin{gathered}
\alpha_{v / l}=\frac{\lambda_{v / l}}{d_{h}}\left[3.66+\frac{0.0668 R e_{v / l} P r_{v / l} \cdot d_{h} / L}{1+0.04\left(R e_{v / l} P r_{v / l} \cdot d_{h} / L\right)^{2 / 3}}\right] \\
F=1+80\left(X^{2}-X^{6}\right) \exp (-0.6 C o)
\end{gathered}
$$

Dimensionless numbers should be computed:

$$
\begin{gathered}
C o=\left\|\frac{\sigma}{g \cdot \Delta \rho}\right\|^{0.5} \\
R e_{l}=\frac{G_{T P} \cdot d_{h}}{\mu_{l}}, R e_{v}=\frac{G_{T P} \cdot d_{h}}{\mu_{v}}
\end{gathered}
$$

Liquid or vapour data should be inserted into the definition of the Prandtl number.

\subsection{Li and Wu correlation}

$\mathrm{Li}$ and $\mathrm{Wu}$ correlation (2010) [23] was based on data for water, refrigerants, ethanol, propane and $\mathrm{CO}_{2}$, $d_{h}=0.16 \div 3.1 \mathrm{~mm}, 3744$ points:

$$
\alpha_{T P}=334 B o^{0.3}\left(B d \cdot R e_{l}^{0.36}\right)^{0.4} \cdot\left(\lambda_{l} / d_{h}\right)
$$

\subsection{Dutkowski correlation}

Dutkowski correlation (2011) [22] was based on data for $\mathrm{R}-134 \mathrm{a}, \mathrm{R}-404 \mathrm{a} ; \quad d_{h}=0.45 \div 2.30 \mathrm{~mm}$, circular minichannels; data for developed boiling:

$$
\alpha_{T P}=0.41 R e_{l}^{0.848} \cdot B o^{0.66} \cdot C o^{-0.62} \cdot\left(\rho_{l} / \rho_{v}\right)^{1.28}(45)
$$

\section{Comparative study of the selected correlations against the experimental data}

\subsection{Experimental data}

Three measurement series for various minichannels with microstructured heating foil, each with a different spatial orientation, were selected for comparison with results obtained by using selected correlations. Figure 2 contains the comparison of experimental and theoretical heat transfer coefficients for the horizontal channel, position $0^{\circ}$; Fig. 3 - the vertical channel, position $90^{\circ}$, and Fig. 4 - for horizontal channel, position $180^{\circ}$. 


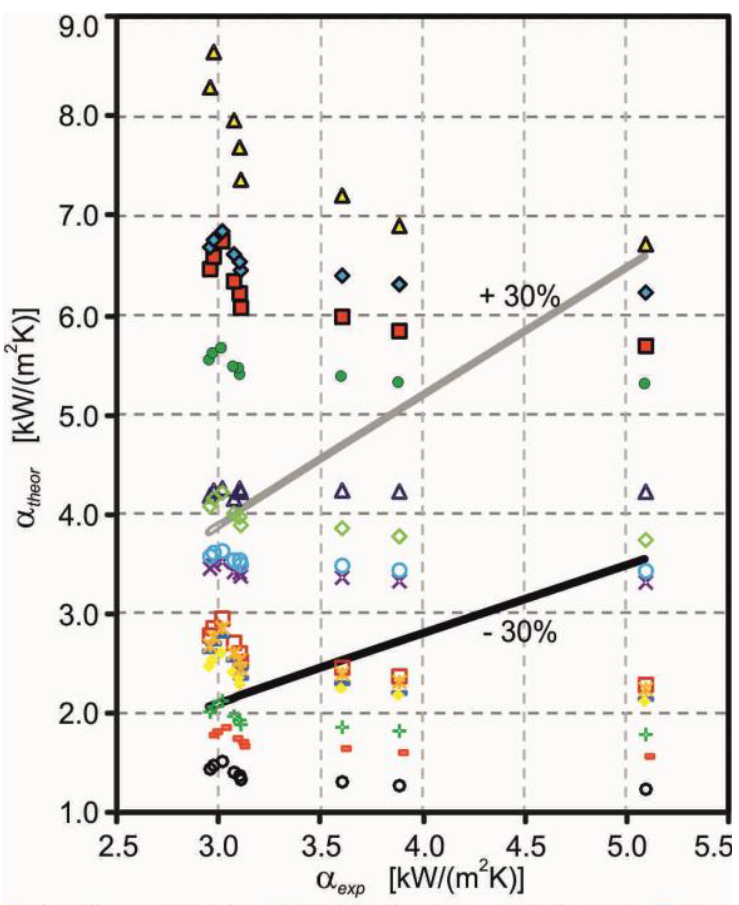

$\diamond$ Kandlikar and Steinke $\times$ Mikielewicz et al. $\Delta$ Dutkowski O Shah - Liu and Winterton $\Delta$ Gungor and Winterton $\mathbf{\square}$ Agostini and Bontemps - Sun and Mishima ※ Kew and Cornwell +Warrier $\square$ Tran et al. - Bertsch et al. Lazarek and Black $\diamond$ Li and Wu o Cooper

Figure 2. Comparison of the experimental heat transfer coefficient with theoretically predicted values, data for horizontal minichannel, position $0^{\circ}$, foil with mini-recesses, $G=286 \mathrm{~kg} /\left(\mathrm{m}^{2} \mathrm{~s}\right), p_{\text {in }}=122 \mathrm{kPa}, \Delta T_{\text {sub }}=43 \mathrm{~K}, X=0.35 \div 0.49$

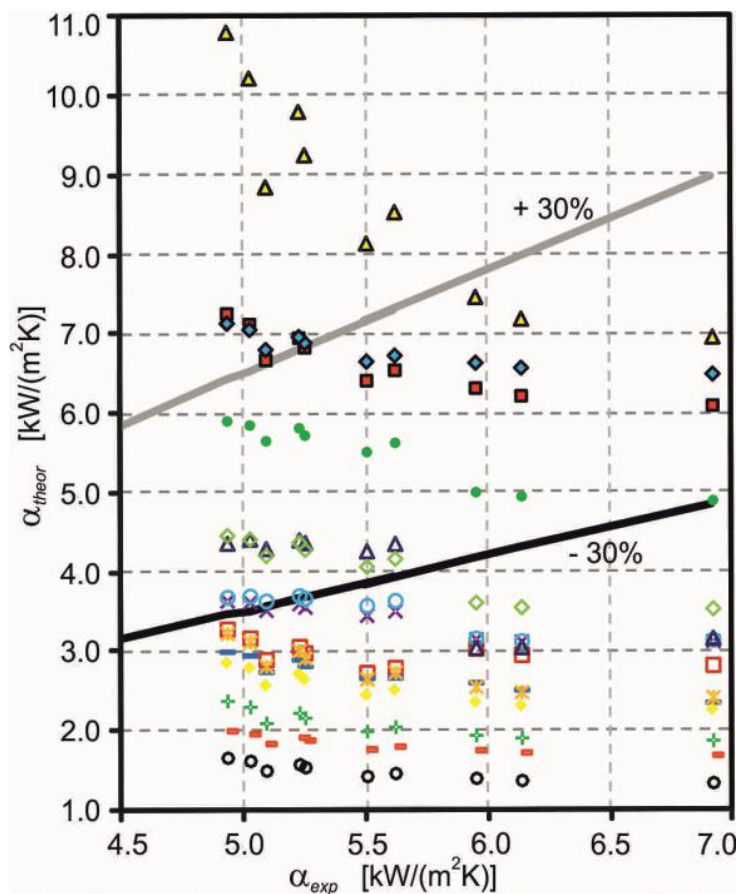

$\diamond$ Kandlikar and Steinke $\times$ Mikielewicz et al. $\quad \Delta$ Dutkowski $\quad$ Shah - Liu and Winterton $\Delta$ Gungor and Winterton $\square$ Agostini and Bontemps

- Sun and Mishima ※ Kew and Cornwell + Warrier $\square$ Tran et al. - Bertsch et al. Lazarek and Black $\diamond$ Li and Wu o Cooper

Figure 3. Comparison of the experimental heat transfer coefficient with theoretically predicted values, data for vertical minichannel, position $90^{\circ}$, foil with mini-recesses,

$G=285 \mathrm{~kg} /\left(\mathrm{m}^{2} \mathrm{~s}\right), p_{i n}=120 \mathrm{kPa}, \Delta T_{\text {sub }}=44 \mathrm{~K}, X=0.39 \div 0.52$

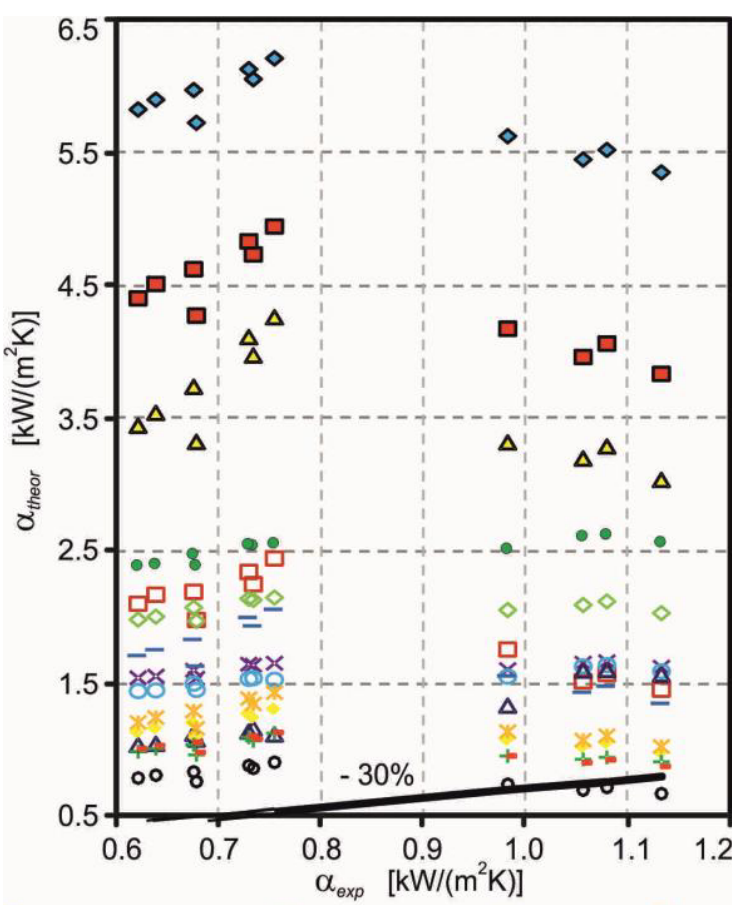

$\diamond$ Kandlikar and Steinke $\times$ Mikielewicz et al. $\Delta$ Dutkowski O Shah - Liu and Winterton $\Delta$ Gungor and Winterton $\mathbf{u}$ Agostini and Bontemps - Sun and Mishima * Kew and Cornwell +Warrier $\square$ Tran et al.

- Bertsch et al. Lazarek and Black $\diamond$ Li and Wu o Cooper

Figure 4. Comparison of the experimental heat transfer coefficient with theoretically predicted values, data for horizontal minichannel, position $180^{\circ}$, foil with micro-recesses, $G=137 \mathrm{~kg} /\left(\mathrm{m}^{2} \mathrm{~s}\right), p_{\text {in }}=120 \mathrm{kPa}, \Delta T_{\text {sub }}=37 \mathrm{~K}, X=0.30 \div 0.49$

Table 1. Summary of calculating the heat transfer data according to correlations selected from literature.

\begin{tabular}{|c|c|c|c|c|}
\hline \multirow{3}{*}{ Correlation } & \multicolumn{4}{|c|}{ Mean relative error $\delta[\%]$} \\
\hline & \multicolumn{3}{|c|}{ position of the minichannel } & \multirow{2}{*}{$\begin{array}{l}\text { all po- } \\
\text { sitions }\end{array}$} \\
\hline & $0^{\circ}$ & $90^{\circ}$ & $180^{\circ}$ & \\
\hline Cooper & 57.93 & 71.22 & 25.76 & 51.85 \\
\hline Shah & 17.20 & 32.91 & 93.51 & 49.32 \\
\hline $\begin{array}{c}\text { Lazarek and } \\
\text { Black } \\
\end{array}$ & 28.32 & 50.99 & 49.69 & 44.17 \\
\hline $\begin{array}{c}\text { Gungor } \\
\text { and Winterton }\end{array}$ & 136.95 & 70.85 & 358.04 & 188.16 \\
\hline $\begin{array}{c}\text { Liu } \\
\text { and Winterton }\end{array}$ & 65.41 & 16.06 & 216.72 & 98.92 \\
\hline Tran et al. & 20.03 & 42.87 & 158.80 & 76.30 \\
\hline $\begin{array}{l}\text { Kandlikar } \\
\text { and Steinke }\end{array}$ & 26.89 & 21.67 & 162.42 & 71.52 \\
\hline Warrier et al. & 40.82 & 59.58 & 37.03 & 46.55 \\
\hline $\begin{array}{c}\text { Agostini } \\
\text { and Bontemps }\end{array}$ & 89.16 & 29.36 & 464.72 & 195.84 \\
\hline $\begin{array}{l}\text { Mikielewicz } \\
\text { et al. }\end{array}$ & 15.52 & 34.35 & 102.22 & 49.07 \\
\hline $\begin{array}{c}\text { Sun and } \\
\text { Mishima }\end{array}$ & 47.77 & 64.73 & 39.18 & 51.18 \\
\hline Bertsch et al. & 24.87 & 47.45 & 119.53 & 65.88 \\
\hline $\begin{array}{c}\text { Kew } \\
\text { and Cornwell } \\
\end{array}$ & 22.42 & 45.86 & 59.02 & 43.80 \\
\hline $\mathrm{Li}$ and $\mathrm{Wu}$ & 98.25 & 30.55 & 641.46 & 259.88 \\
\hline Dutkowski & 34.43 & 32.32 & 59.92 & 43.34 \\
\hline
\end{tabular}


The correlation by Kandlikar and Steinke was proposed for the laminar flow. Due to the fact that the authors of this correlation have not cited the coefficient $F_{F l}$ for FC-72, it should be assumed in the calculation. For $\mathrm{FC}-72$, as fluorohydrocarbon, the arithmetic mean value $\left(F_{F l}=1.7\right)$ from coefficients cited by Kandlikar for R-11 and R-113 and R-12 was calculated.

The mean relative error was determined from the equation:

$$
\delta=\frac{1}{N} \sum_{x=1}^{N}\left|\frac{\alpha(x)_{\text {theor }}-\alpha(x)_{\exp }}{\alpha(x)_{\exp }}\right|
$$

Table 1 contains mean errors obtained for selected theoretical correlations separately - for each of the three positions of the channel and averaged data - for data on all analyzed spatial orientations of the channel.

\subsection{Remarks and comments on data analysis}

The following was found on the basis of data presented in Figs. 2-4 and in Table 1:

- For the horizontal minichannel, position $0^{\circ}$ (Fig. 2): the highest compliance was achieved by using Mikielewicz et al. correlation and mean relative error occurred as below $16 \%$. Good compliance (most coefficient values within the limits of error of $\pm 30 \%$ ) was found by using the following correlations: Tran et al., Kew and Cornwell, Bertsch et al., Kandlikar and Steinke, Lazarek and Black, Dutkowski (mean relative error max. 35\%);

- $\quad$ For the vertical minichannel, position $90^{\circ}$ (Fig. 3): the best compliance of results was obtained by application of Liu and Winterton correlation - all data, calculated in accordance with this dependence was within the limit of error of $\pm 30 \%$, mean relative error was approx. $16 \%$. The majority of data calculated with the following correlations: Kandlikar and Steinke, Agostini and Bontemps, $\mathrm{Li}$ and $\mathrm{Wu}$, Dutkowski, Shah, Mikielewicz et al., was characterized by mean relative error below $35 \%$. Values of the heat transfer coefficient slightly higher than the values for the horizontal minichannel, position $0^{\circ}$ were obtained.

- $\quad$ For horizontal minichannel, position $180^{\circ}$ (Fig. 4): the experimental heat transfer coefficient was considerably lower in comparison to values obtained for the vertical minichannel, position $90^{\circ}$ and for the horizontal minichannel, position $0^{\circ}$. Values of the experimental heat transfer coefficient reach maximally $1200 \mathrm{~W} /\left(\mathrm{m}^{2} \mathrm{~K}\right)$ and they are close to the values obtained for the single phase convection and subcooled boiling. Experimental void fraction for the data related to saturated boiling and the cross-section at the distance of; $0.3 \mathrm{~m}$ from the inlet approaches 1 , and the high drop in the coefficient value is observed by the change in mechanism of heat transfer due to the considerably higher share of the vapour fraction. The highest compliance was achieved by applying Cooper correlation (mean relative error approx. $26 \%$ ). In most results obtained from Warrier et al., correlation and Sun and Mishima correlation achieved mean relative error below $40 \%$.

It was also found that the assessment of based only on averaged values of the relative error (see Table 1), common for all spatial orientations often leads to wrong conclusions. Some correlations allow to forecast the values of the heat transfer coefficient only for a certain channel position or for two positions.

\section{New correlation}

\subsection{Definition of surface development parameter}

The parameter reflecting the level of surface development $\Gamma$, compliant with the following formula:

$$
\Gamma=\frac{\left(1+V_{r e c}\right) \cdot H \cdot n \cdot \varepsilon}{S_{d e v}}
$$

where $V_{\text {rec }}$ - share of the recesses in the analyzed section of the microstructured area; $H$ - sum of recesses' heights in the microstructured length for analysis $(\mu \mathrm{m})$; $\varepsilon$ - diameter or the longest part of the recess's length of the microstructured surface $(\mu \mathrm{m})$, (the longest one is equal to the size of the analyzed section); $n$ - number of recesses with the highest dimensions, on the length of microstructured surface taken for analysis, $S_{d e v}-$ microstructured surface, $\mu \mathrm{m}^{2}$.

The following results were obtained on the basis of microstructured surfaces, used in the study:

- heating foil with micro recesses: $V_{\text {rec }}=0.0628$, $H=10 \mu \mathrm{m}, \varepsilon=30 \mu \mathrm{m}, \quad n=1, \Gamma=0.032$;

- heating foil with mini recesses: $V_{\text {rec }}=0.2749$, $H=2.2 \mu \mathrm{m}, \varepsilon=100 \mu \mathrm{m}, \quad n=1, \Gamma=0.028$.

\subsection{Correlation for saturated flow boiling}

The following equation was obtained for saturated flow boiling:

$$
N u_{\text {theor }}=22.5 \cdot \Gamma \cdot(P e \cdot B o)^{0.64} \cdot W e^{0.46}
$$

In order to estimate regression parameters values, 4961 measurement results for FC-72 developed nucleate boiling in the minichannel were accounted for. $N u_{\text {theor }}$ number calculated from eq. (48), was compared with Nusselt number, determined experimentally, eq. (1b) Fig. 5. Standard errors of calculated Nusselt number, amount to 0.06 , whereas the determination coefficient $R^{2}$, being the measure of regression line matching accuracy (in the logarithmic system) - 0.91. Almost all measurements $(95 \%)$ show congruence with calculations with the tolerance $\pm 35 \%$.

Equation (48) was checked for the following range of parameters: $444 \leq R e_{l} \leq 1130 ; 5.13 \cdot 10^{-4} \leq B o \leq 1.35 \cdot 10^{-3}$; $9.08 \leq P r_{l} \leq 11.60 ; 1.23 \leq W e \leq 6.25$; $1.83 \leq(\mathrm{Pe} \cdot \mathrm{Bo}) \leq 10.3 ; \quad 0.14 \leq X \leq 0.48$; $0.028<\Gamma<0.032$. 


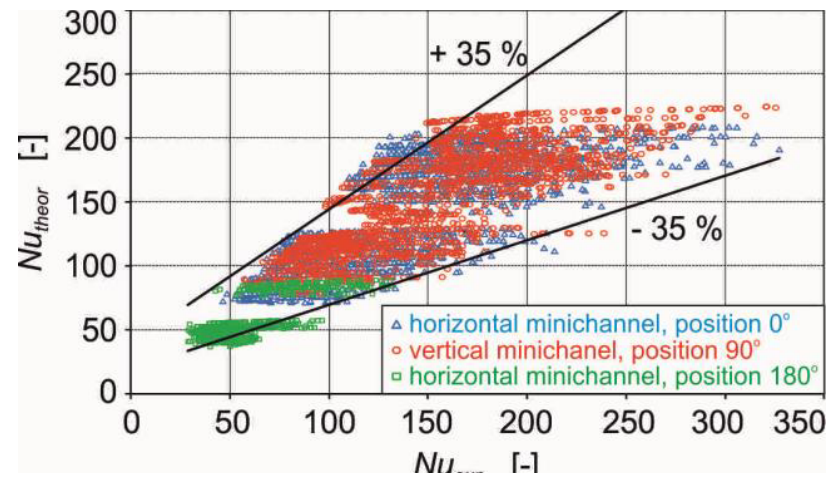

Figure 5. Equation (48) for saturated boiling when FC-72 flows through a minichannel (1 $\mathrm{mm}$ deep) with microstructured heating surface of low development level; for data obtained in 3 various spatial orientations of the channel, various tags are applied (description in the legend)

\subsection{Correlation for subcooled flow boiling}

For boiling incipience and subcooled boiling the following form of the equation was obtained:

$$
N u_{\text {theor }}=5.2 \cdot \Gamma^{-4} \cdot\left(P e_{l} \cdot B o\right)^{0.53} \cdot W e^{0.12}
$$

For 2438 measurement results for FC-72, R-123 and R-11 for boiling incipience and subcooled boiling in a minichannel with plain or microstructured heating surface were accounted for. Data for various spatial orientations of the channel were taken into account, in the range of $0-360^{\circ}$. N $N u_{\text {theor }}$ number calculated from eq. (49) - was compared with Nusselt number, determined experimentally, eq. (1b). Results are presented in Fig. 6. Standard errors of calculated Nusselt number, amount to approx. 0.1, whereas the determination coefficient $R^{2}=0.69$. For the majority of the data (84\%), almost all measurements show congruence with calculations with the tolerance $\pm 35 \%$.

Equation (49) was checked for the following range of parameters: $411 \leq R e_{l} \leq 4730 ; 1.21 \cdot 10^{-4} \leq B o \leq 1.86 \cdot 10^{-3}$; $2.86 \leq P r_{l} \leq 15.46 ; 0.19 \leq W e \leq 11.79$; $0.99 \leq\left(P e_{l} \cdot B o\right) \leq 15.23 ; 0<\Gamma<0.032$.

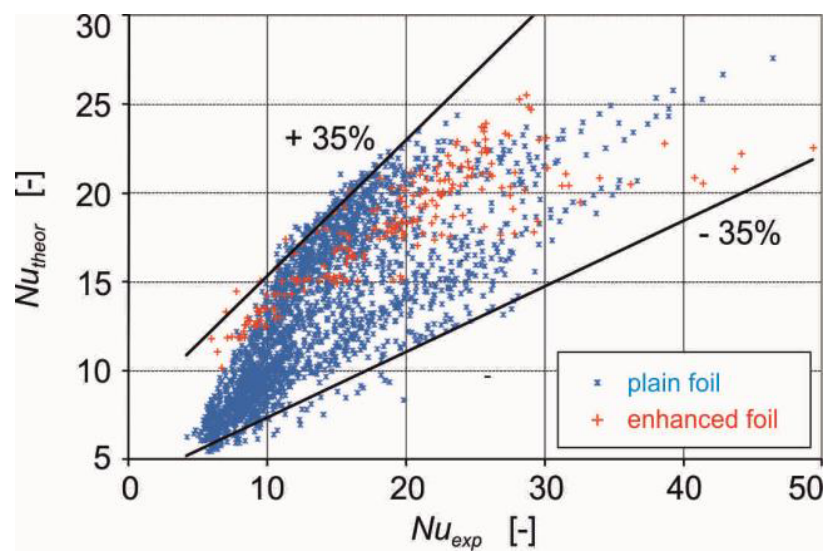

Figure 6. Equation (49) for boiling incipience and subcooled boiling for R-123, R-11 and FC-72 in a minichannel of $0.7 \div 1.5 \mathrm{~mm}$ depth, of various spatial orientation, heated asymmetrically by the smooth or microstructured surface
Figure 7 summarizes the results of the proposed relationship (49) and data obtained by the application of data obtained by transformation of Dittus-Boelter, eq. (4), converted into the following equation:

$$
N u_{\text {theor } r_{-} D-B}=0.023 \cdot \operatorname{Re}_{l}^{0.8} \cdot \mathrm{Pr}_{l}^{0.4}
$$

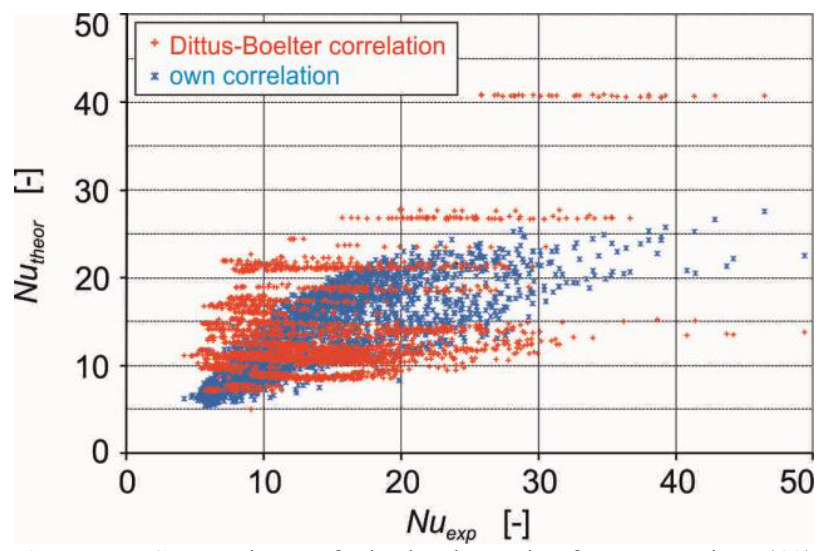

Figure 7. Comparison of obtained results from equation (49) with Dittus-Boelter correlation (50)

A high compliance of data obtained from the author's equation (49) in comparison with data obtained from Dittus-Boelter correlation (50), used for the description of the heat transfer during single phase convection in channels in turbulent flow conditions. Majority of the author's data was applicable to boiling incipience, which begins with an increase heat transfer coefficient, featuring relatively low coefficient values in comparison to those obtained to saturated boiling.

\section{Conclusions}

In order to compare experimental heat transfer coefficients to results of other authors, measurement series for three orientations of the channel with microstructured heating wall were selected: horizontal, position $0^{\circ}$ and $180^{\circ}$ and vertical. 15 selected correlations for boiling heat transfer were applied in calculations. It was found that most correlations enables the predicting of heat transfer coefficient within an acceptable error limit $( \pm 30 \%)$ only in specific orientations of the channel. For the position $0^{\circ}$ the highest compliance occurred when Mikielewicz et al. correlation was applied, for the position $90^{\circ}$ - when Liu and Winterton correlation was used and for the position $180^{\circ}$ - by the application of Cooper correlation (for pool boiling). Mean relative errors for the determination of heat transfer coefficient together for all orientations of the minichannel and separately for each position were calculated. Some correlations allow to forecast the values of the heat transfer coefficient only for a certain channel position.

It should be underlined that the author's experimental results concerned flow boiling in the channel with the microstructured heating surface, while the correlations used in calculations reflected boiling on plain surfaces. Because the level of the development of the surfaces applied in the study is not high and it amounts to several per cent, it does not have a significant effect to obtained results. However, application of heating surfaces with a higher level of development, should lead to higher values 
of the heat transfer coefficient. That is why universal correlation equations used in studies on the flow boiling should also include the surface development parameter.

The author's proposed correlation, with account taken for the surface development parameter, in two forms: for developed boiling and for boiling incipience and subcooled boiling. For these equations, the majority of measurements show congruence with calculations with small tolerance $\pm 35 \%$ which confirm a good choice for the sake of heat transfer calculations. The compliance of proposed correlations in heating area with the considerably higher level of development. Currently, plans on using porous metallic structures: sintered capillary-porous structure and sintered metallic powder are underway.

\section{Acknowledgments}

The research has been financially supported by the National Scientific Center granted on the basis of decision No DEC-2013/09/B/ST8/02825.

\section{Nomenclature}

$A$ - cross-section, $\mathrm{m}^{2}$

$c_{p} \quad$ - specific heat, $\mathrm{J} /(\mathrm{kg} \mathrm{K})$

$a, b, c, d, E, F, F_{F l}, f, N, P, R_{M-S}, S-$

- coefficients

$d_{h} \quad$ - hydraulic diameter, $\mathrm{m}$

$G \quad$ - mass flux (density), $\mathrm{kg} /\left(\mathrm{m}^{2} \mathrm{~s}\right)$

$H$ - sum of recesses' heights, $\mu \mathrm{m}$

$h_{l v} \quad$ - latent heat of vaporization, $\mathrm{J} / \mathrm{kg}$

I - current supplied to the heating foil, A

$L \quad$ - length, m

$M \quad$ - molecular mass of the fluid, $\mathrm{kg} / \mathrm{kmol}$

$n$ - number of recesses

$p$ - pressure, $\mathrm{N} / \mathrm{m}^{2}$

$q_{w} \quad$ - heat flux density, $\mathrm{W} / \mathrm{m}^{2}$

$R^{2} \quad$ - determination coefficient

$R a$ - surface roughness parameter, $\mu \mathrm{m}$

$S_{d e v}$ - developed (microstructured) surface, $\mu \mathrm{m}^{2}$

$T$ - temperature, $\mathrm{K}$

$u$ - flow velocity, $\mathrm{m} / \mathrm{s}$

$V_{\text {rec }}$ - share of the recesses

$X$ - vapour quality

\section{Greek}

$\alpha \quad$ - heat transfer coefficient, $\mathrm{W} /\left(\mathrm{m}^{2} \mathrm{~K}\right)$

$\Gamma \quad$ - surface development parameter

$\Delta T_{\text {sub }}$ - inlet liquid subcooling $\left(T_{\text {sat }}-T_{l}\right)_{i n}, \mathrm{~K}$

$\Delta U$ - the voltage drop across the foil, $\mathrm{V}$

$\delta \quad$ - width, m; standard error

$\varepsilon \quad$ - diameter or the longest size of the recess, $\mu \mathrm{m}$

$\lambda$ - thermal conductivity, $\mathrm{W} /(\mathrm{m} \mathrm{K})$

$\mu \quad$ - dynamic viscosity, $\mathrm{kg} /(\mathrm{m} \mathrm{s})$

$\rho \quad$ - density, $\mathrm{kg} / \mathrm{m}^{3}$

$\sigma$ - surface tension, $\mathrm{N} / \mathrm{m}$

\section{Indexes}

$c b \quad$ - convective boiling $r \quad$ - reduced

$D$ - $B$ - Dittus-Boelter ref - referenced

exp - experimental sat - saturation

$$
\begin{array}{ll}
F & \text { - foil } \\
i n & \text { - at the inlet } \\
l & \text { - liquid } \\
n b & \text { - nucleate boiling }
\end{array}
$$

Dimensionless numbers

$$
\begin{aligned}
& B o=q_{w} /\left(G \cdot h_{l v}\right) \\
& F r=G^{2} /\left(\rho^{2} \cdot g \cdot d_{h}\right) \\
& \operatorname{Pe}=\operatorname{Re} \cdot \operatorname{Pr} \\
& \operatorname{Re}=\left(G \cdot d_{h}\right) / \mu
\end{aligned}
$$

$$
\begin{array}{ll}
S P & \text { - single phase } \\
\text { theor } & \text { - theoretical } \\
T P & \text { - two phase } \\
v & \text { - vapour }
\end{array}
$$

$$
\text { (Co defined in the text) }
$$

$$
\begin{aligned}
& B d=\left[g\left(\rho_{l}-\rho_{v}\right) \cdot d_{h}^{2}\right] / \sigma \\
& N u=\left(\alpha \cdot d_{h}\right) / \lambda_{l} \\
& \operatorname{Pr}=\left(\mu \cdot c_{p}\right) / \lambda \\
& W e=\left(u^{2} \cdot d_{h} \cdot \rho\right) / \sigma
\end{aligned}
$$

\section{References}

1. M. Piasecka, Int. J. Heat and Mass Transf. 66, 472-488 (2013)

2. M. Piasecka, B. Maciejewska, Exp. Thermal Fluid Sci. 44, 23-33 (2013)

3. M. Piasecka, Heat Mass Transf. 49, 261-271 (2013)

4. M. Piasecka, Metrology and Meas. Sys. XX, 205-216 (2013)

5. M. Piasecka, Exp. Heat Transf. 27, 231-255 (2014)

6. M. Piasecka, Heat Transf. Eng. 35, 903-912 (2014)

7. M.G. Cooper, Adv. Heat Transfer 16, 157-239 (1984)

8. R. Pastuszko, Exp. Thermal Fluid Sc. 38, 149-164 (2012).

9. R. Pastuszko, M. Piasecka, J. Physics Conf. Ser. 395, No. 012137 (2012).

10. M.M. Shah, ASHRAE Trans. 88, 185-196 (1982)

11. K.E. Gungor, R.H.S. Winterton, Chem. Eng. Research and Design 65, 148-156 (1987)

12. Z. Liu, R.H.S. Winterton, Int. J. Heat Mass Transf. 34, 2759-2766 (1991)

13. G.M. Lazarek, S.H. Black, Int. J. Heat Mass Transf. 25, 945-960 (1982)

14. T. Tran, M.W. Wambsganss, D.M. France, Int. J. Multiphase Flow 22, 485-498 (1996)

15. P.A. Kew, K. Cornwell, Appl. Thermal Eng. 17, 705-715 (1997)

16. G. Kandlikar, M.E. Steinke, Proc. 12th Int. Heat Transfer Conf., Grenoble, France, Paper No. 1178 (2002)

17. G.R. Warrier, V.K. Dhir, L.A. Momoda, Exp. Thermal Fluid Sci. 26, 53-64 (2002)n,

18. B. Agostini, A. Bontemps, Vertical flow boiling of refrigerant R134a in small channels, Int. J. Heat Fluid Flow 26, 296-306 (2005)

19. D. Mikielewicz, J. Mikielewicz, Tesmar J., Int. J. Heat Mass Transf. 50, 3949-3956 (2007)

20. L. Sun, K. Mishima, Int. J. Heat Mass Transf. 52, 5323-5329 (2009)

21. S.S. Bertsch, E.A. Groll, S.V. Garimella, Int. J. Heat Mass Transf. 51, 4775-4787 (2009)

22. W. Li, Z. Wu, Int. J. Heat Mass Transf. 53, 1778-1787 (2010)

23. K. Dutkowski, Heat transfer and pressure drop during single-phase and two-phase flow in minichannels, (Univ. Publish. Koszalin Univ. of Technology, Koszalin, 2011) (in Polish) 